\title{
STATISTICALLY OPTIMIZED AND BOX-BEHNKEN DESIGN ASSISTED METHOD DEVELOPMENT AND VALIDATION OF AN ANTIPSYCHOTIC MEDICATION OLANZAPINE AND ITS RELATED IMPURITIES BY REVERSE-PHASE HPLC-UV SPECTROSCOPY
}

\section{IRSHAD ALAM ${ }^{*}$, AQUIL-UR-RAHIM SIDDIQUI ${ }^{2}$}

1Research Scholar, Faculty of Science and Technology, Dr. Babasaheb Ambedkar Marathwada University, Aurangabad, Maharashtra, India, ${ }^{2}$ Shri Bhagwan College of Pharmacy Affiliated to Dr. Babasaheb Ambedkar Marathwada University, Aurangabad, Maharashtra, India Email: irshadsips_babu@yahoo.co.in

Received: 13 Mar 2021, Revised and Accepted: 31 May 2021

\section{ABSTRACT}

Objective: Statistically designed and Box-Behnken design (BBD) assisted reversed-phase high-performance liquid chromatography-ultraviolet (HPLC-UV) method was developed and validated for the identification of an antipsychotic medication Olanzapine and its organic impurities in pure drug along with forced degradation studies.

Methods: The present developed method employed BBD optimized chromatographic conditions comprising of an Inertsil ODS 3V analytical column with dimension $250 \mathrm{~mm} \times 4.6 \mathrm{~mm}$ and particle size $5 \mu$. The isocratic mobile phase was used as a mixture of monobasic sodium phosphate buffer $(0.01 \mathrm{M}, \mathrm{pH} 6)$, methanol and acetonitrile in the proportion of 40/30/30, v/v. The mobile phase flow rate and UV $\lambda$ max was $1 \mathrm{ml} / \mathrm{min}$ and $260 \mathrm{~nm}$, respectively. The method was optimized by Box-Behnken design using design expert software, comprising of three factors for Olanzapine for instance flow rate (A), mobile phase composition (B) and $\mathrm{pH}(\mathrm{C})$ while resolution between Olanzapine related compound A and Olanzapine related compound $\mathrm{B}\left(\mathrm{Y}_{1}\right)$ and tailing of Olanzapine $\left(\mathrm{Y}_{2}\right)$ were taken as a response.

Results: Application of BBD yielded statistically designed method with excellent quality parameters achieved in terms of linearity with the coefficient of correlation $\left(\mathrm{R}^{2}>0.9999\right)$, limit of detection (LOD, 0.0023-0.16 $\mu \mathrm{g} / \mathrm{ml}$ ), the limit of quantification (LOQ, $0.007-0.39 \mu \mathrm{g} / \mathrm{ml}$ ), accuracy (99$100 \%)$ and precision $((2 \%$, relative standard deviation $(\% \mathrm{RSD})$ were evaluated as per latest available procedures.

Conclusion: Forced degradation conditions were carried out, demonstrated that the optimized method was stable and no any interfering peaks eluting at the similar retention time of the studied compounds. The method was found to be stable, easy, rugged and robust, could be applied for the similar types of the pure drug.

Keywords: Olanzapine, Forced degradation, Box-Behnken design, Experimental design, HPLC-UV

(C) 2021 The Authors. Published by Innovare Academic Sciences Pvt Ltd. This is an open access article under the CC BY license (https://creativecommons.org/licenses/by/4.0/) DOI: https://dx.doi.org/10.22159/ijap.2021v13i4.41427. Journal homepage: https://innovareacademics.in/journals/index.php/ijap

\section{INTRODUCTION}

Pure drug, Olanzapine (OLZ) is a thienobenzodiazepine derivative, chemically called as 2-methyl-4-(4-methyl-1-piperazinyl)-10H-thieno [2-3-b][1-5]benzodiazepine. It is a synthetic, atypical, antipsychotic agent widely used in the treatment of schizophrenia and related disorders. OLZ is highly potent antagonist at Dopamine $\mathrm{D}_{2}$ and especially, serotonin $5 \mathrm{HT}_{2 \mathrm{~A}}$ receptors [1-5]. It has pKa value of 10.57 , as cited from the drug bank and mentioned in the product monograph of Mylan. Extensive study revealed various analytical methods for instance titrimetry [6], spectrophotometry [7], high-performance thin layer chromatography [8], etc. had been used for quantification of OLZ. Several chromatographic methods were reported for the analysis of OLZ in pharmaceutical and biological samples, in one of the technique, HPLC with UV-detection was used [9]. Literature revealed RP-HPLC method for the determination of OLZ by Murthy AR et al. [10]. They had developed a gradient system using HPLC (Shimadzu class LCSeries), system controlle SCL 10VP, with LC-10AT pump with C18 (150 $\mathrm{mm} \times 4.6 \mathrm{~mm}$ ) column by using Shimadzu class VP-5.0 software. In another method developed by Rao RN et al. [11], used Inertsil ODS 3V $(250 \mathrm{~mm} \times 4.6 \mathrm{~mm}), 5 \mu$ column with a gradient programme for estimation of OLZ and its impurities by using mobile phase composition of $0.2 \mathrm{M}$ ammonium acetate and acetonitrile at $254 \mathrm{~nm}$ wavelength. The above reported methods were either poorly sensitive with high run time or they had very narrow linear concentration ranges, so, in the present study we had developed and validated a stability-indicating method for simultaneous estimation of OLZ in API and its organic impurities by strictly implementing quality by design (QBD), as in the current scenario as per ICH guidelines and other Europe medicines agencies had strictly ordered implementation of QBD [13]. The selected experimental design in present investigation was Box-Behnken design (BBD) including design expert 10.0.7.0 software (Stat-Ease Inc., Minneapolis, Minnesota) and the entire procedure obeyed ICH guidelines. The opted parameters in the current analysis as per BBD were, flow rate (A), mobile phase composition (B) and $\mathrm{pH}(\mathrm{C})$ as variables while resolution between RC A and RC B ( $\left.\mathrm{Y}_{1}\right)$ and tailing of OLZ $\left(\mathrm{Y}_{2}\right)$ were taken as response that showed slight variation in mobile phase and flow rate affected the response while $\mathrm{pH}$ had no influence on these variables estimated by trails according to factorial design. We have developed an innovative, simple, cost-effective, RP-HPLC method which was duly validated by statistical parameters, precision, accuracy, recovery, limit of detection, limit of quantitation and force degradation. The method is highly novel since, till date there is no evidence of detection of OLZ and its organic impurities named as Olanzapine related compound A (RC A), Olanzapine related compound B (RC B) and Olanzapine related compound C (RC C) along with forced degradation studies simultaneously by single isocratic method, the entire procedure was highly efficient as it was based on QBD and strictly follows ICH guidelines USFDA specifications, so it can be used widely for simultaneous estimation of OLZ along with its organic impurities as shown in fig. 1 in API form with high purity and compatibility.

\section{MATERIALS AND METHODS}

\section{Chemicals and reagents}

HPLC grade methanol and acetonitrile were used. OLZ, RC A, RC B (Desmethyl impurity), and RC C (Hydroxyl impurities) were received as gift samples from Alkem laboratories (P) Ltd, Mumbai. Sodium hydroxide $(\mathrm{NaOH})$ was obtained from Rankem, Haryana, India. Sonicator from Lab companion (Billerica, MA, USA) was used. Analytical balance from Mettler-Toledo GmbH (Giessen, Germany) and the $\mathrm{pH}$ meter from Lab India (Mumbai, India). The mobile phase was used as a diluent for standard and sample preparation.

\section{Standard preparation of OLZ}

OLZ working standard was prepared by precisely weighing $(50 \mathrm{mg})$, it was dissolved in $50 \mathrm{ml}$ of mobile phase to obtain the stock solution 
$(1000 \mu \mathrm{g} / \mathrm{ml})$. Stock solution was used for further dilution and prepared solutions at various concentrations $(10,20,40,60,80$, and $100 \mu \mathrm{g} / \mathrm{ml}$ ). Samples and standards were filtered through $0.45 \mu \mathrm{m}$ membrane filter before use.
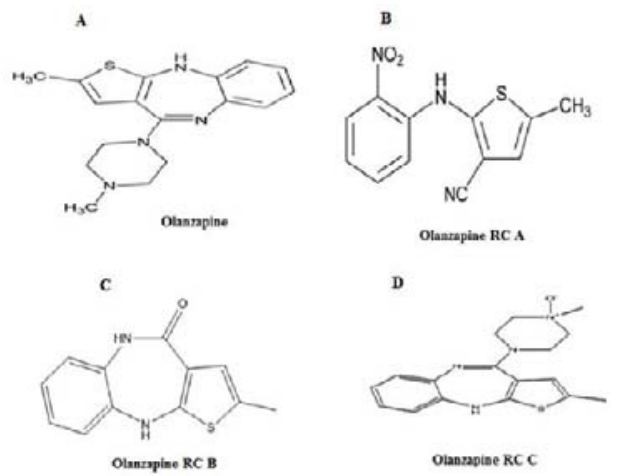

Fig. 1: Structure of olanzapine and its impurities

\section{Standard preparation of organic impurities (OI)}

A $2.5 \mathrm{mg}$ of OLZ working standard (RC A, RC B and RC C) was accurately weighed and transferred into $20 \mathrm{ml}$ volumetric flask followed by $15 \mathrm{ml}$ diluent addition and sonicated. Finally, the total volume was make up with diluent and agitated, the solution was filtered through $0.45 \mu \mathrm{m}$ membrane filter prior to use.

\section{Sample preparation of OI}

A $25 \mathrm{mg}$ of OLZ was accurately weighed and transferred into $20 \mathrm{ml}$ of added $15 \mathrm{ml}$ of prepared diluent followed by sonication. The final volume was prepared with further addition of diluent.

\section{OLZ preparation and spiking with OI}

A $25 \mathrm{mg}$ of OLZ was accurately weighed and transferred into $20 \mathrm{ml}$ of volumetric flask. $2 \mathrm{ml}$ of OLZ standard OI was added to it. Then 15 $\mathrm{ml}$ of diluent was added and sonicated. Finally, the total volume was made up with diluent and filtered through $0.45 \mu$ membrane filter.

\section{Estimation of OLZ}

Accurately weighed and transferred $50.0 \mathrm{mg}$ of OLZ in $100 \mathrm{ml}$ of the volumetric flask, then to this added $75 \mathrm{ml}$ of diluent and placed on a sonicator to dissolve. Finally, the volume was made up with diluent, then again further dilution was done. $5 \mathrm{ml}$ of the prepared solution was further diluted with $50 \mathrm{ml}$ of diluent, mixed and filtered through $0.45 \mu$ filter.

\section{Instrumentation \\ High-performance liquid chromatography-ultraviolet (HPLC- UV)}

HPLC-UV system equipped with a thermostatted autosampler, binary pump, degasser, column compartment and injector with a variable loop (1-200 $\mu$ l) (Santa Clara, CA, USA). The reversed-phase analytical column Inertsil ODS 3V with a dimension of $250 \mathrm{~mm} \times 4.6$ $\mathrm{mm}$, particle size $5 \mu$ (Merck KGaA, Darmstadt, Germany) was used to separate the target analytes. The system was monitored using Chromeleon software (Santa Clara, CA, USA).

The chromatographic conditions were applied as mobile phase a buffer solution comprising of $0.01 \mathrm{M}$ Monobasic sodium phosphate dissolved in $1000 \mathrm{ml}$ of water with $\mathrm{pH}$ 6, adjusted with $1 \mathrm{~N} \mathrm{NaOH}$. The buffer solution was filtered through $0.45 \mu$ membrane filter, then it was mixed with methanol and acetonitrile in the ratio of 40:30:30 and finally sonicated for $10 \mathrm{~min}$. The mobile phase was used in isocratic mode with a flow speed of $1 \mathrm{ml} / \mathrm{min}$. The sample injection volume was $10 \mu \mathrm{l}$. The detection of target compounds was carried out using UV detector at wavelength $260 \mathrm{~nm}$, the observed chromatogram was represented in fig. 2 .
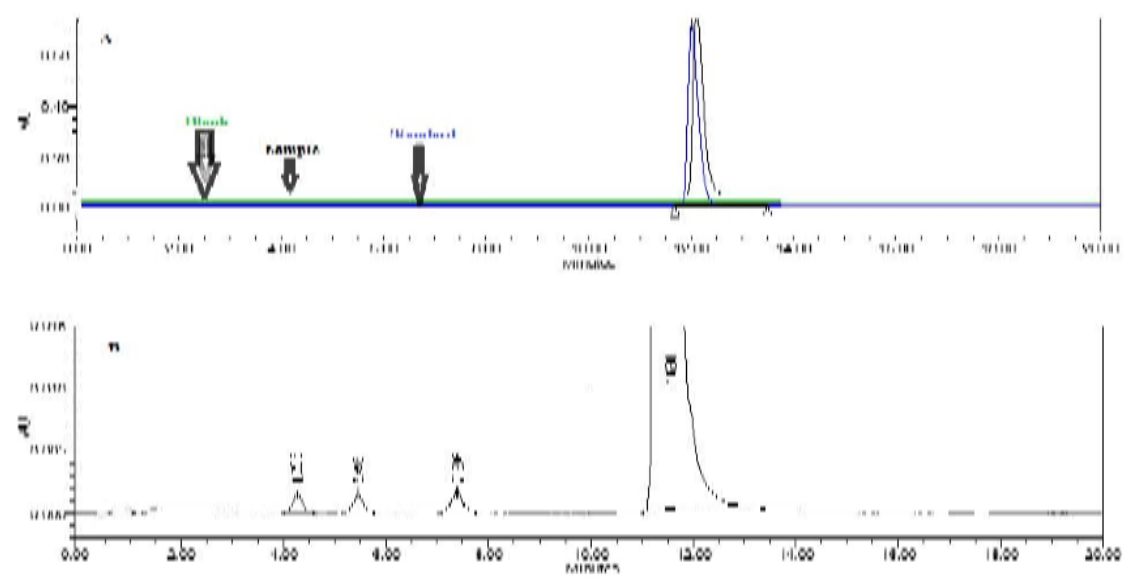

Fig. 2: Chromatogram of standard overlay (A) and standard with impurities (B)

\section{Experimental design and method development}

In the present developed method estimation of OLZ along with its OI in API form was designed according to the suitability of composition of various solvents by varying ratio of buffer mixture as per respective $\mathrm{QBD}$, the selected variables were flow rate $(\mathrm{A})$, mobile phase-organic phase (B) and $\mathrm{pH}(\mathrm{C})$, along with selected response as resolution between RC A and RCB ( $\left.\mathrm{Y}_{1}\right)$ and tailing of OLZ $\left(\mathrm{Y}_{2}\right)$. The method was optimized using response surface methodology by applying BBD and implementing the software known as Design Expert 10.0.7.0 software. The applied design matrix yields 18 experimental runs, based on the conditions of parameters suggested according to table 1 and by applying the second-order polynomial equation for evaluation of all response variables by the application of following equation:
$\mathrm{Y}=$

$\mathrm{B}_{0}+\mathrm{B}_{1} \mathrm{X}_{1}+\mathrm{B}_{2} \mathrm{X}_{2}+\mathrm{B}_{3} \mathrm{X}_{3}+\mathrm{B}_{12} \mathrm{X}_{1} \mathrm{X}_{2}+\mathrm{B}_{13} \mathrm{X}_{1} \mathrm{X}_{3}+\mathrm{B}_{23} \mathrm{X}_{2} \mathrm{X}_{3}+\mathrm{B}_{1} \mathrm{X}_{1}{ }^{2}+\mathrm{B}_{2} \mathrm{X}_{2}{ }^{2}+\mathrm{B}$ ${ }_{3} \mathrm{X}_{3}{ }^{2}$

Where, $\mathrm{B} 0, \mathrm{~B}_{1}, \mathrm{~B}_{2}$ and $\mathrm{B} 3$ were regression co=efficient, $\mathrm{X} 1, \mathrm{X} 2$ and $\mathrm{X} 3$ were the factors studied and $\mathrm{Y}$ was the obtained response corresponding to each factor. Lastly, analysis of variance (ANOVA) was applied to obtain the significant difference from the design matrix. The data obtained by using ANOVA was represented in table 2 and table 3 respectively. The aptness of mobile phase composition was recognized by varying the ratio of mixture of $0.01 \mathrm{M}$ Monobasic sodium phosphate buffer (adjusted to $\mathrm{pH} 6.0$ ), $1 \mathrm{~N} \mathrm{NaOH}$, methanol and acetonitrile, by employing mentioned software. The confirmation for the mixture of acetonitrile and buffer together, as 
selected mobile phase was based on earlier analysis theoretical available data. System performance was evaluated by corroborating the system suitability parameters. The system precision was calculated by six replicate injections of OI standard preparation and assay of standard preparation. All essential chromatographic characteristics like, relative standard deviation, peak tailing, theoretical plate number and resolution were measured along with system suitability parameters representing the system, method and the column performance. Robustness parameters were estimated by implementation of experimental design. System suitability was carried out as per USP on an immediately prepared standard solution and evaluating parameters were determined by using above chromatographic conditions for assay [14-18].

\section{RESULTS AND DISCUSSION}

The present developed method yields convenient preparation along with lower retention time and maximum impurities detection for analysis. It was observed that implementation of $\mathrm{QBD}$ on the currently developed method yielded enhanced results as compared with presently available literature. The same isocratic programme for estimation of OLZ in API form and its associated organic impurities was highly innovative, as till date there is no literature evidence reported regarding the same with run time of $20 \mathrm{~min}$. Even the stability assessment was performed by determination of various forced degradation study. The suitability of flow rate, column temperature, mobile phase and $\mathrm{pH}$ was based on the system suitability, linearity, accuracy, sensitivity and forced degradation study. The various combinations available from BBD suggested the most optimum constituents of mobile phase comprising of $0.01 \mathrm{M}$ Monobasic sodium phosphate buffer $(\mathrm{pH} 6)$, methanol and acetonitrile in the ratio of 40:30:30. The mobile phase flow rate 1.0 $\mathrm{ml} / \mathrm{min}$ with UV-detection at $260 \mathrm{~nm}$, representing the excellent chromatographic separation of OLZ and its impurities. The optimized chromatographic conditions along with experimental design data was represented in table 1 and table 2, respectively. The obtained data for ANOVA was represented in table 3.

Table 1: Data representing optimized chromatographic conditions and investigated range during robustness testing data

\begin{tabular}{|c|c|c|c|c|c|c|c|c|c|}
\hline Factor & Name & Units & Type & Minimum & Maximum & Low level & High level & Mean & Std. dev. \\
\hline $\mathrm{A}$ & Flow & $\mathrm{ml} / \mathrm{min}$ & Numeric & 0.8 & 1.2 & $-1.000=0.8$ & $1.000=1.2$ & 1 & 0.137199 \\
\hline B & Mobile Phase (Organic) & $\%$ & Numeric & 55 & 65 & $-1.000=55$ & $1.000=65$ & 60 & 3.42997 \\
\hline $\mathrm{C}$ & $\mathrm{pH}$ & NA & Numeric & 5.8 & 6.2 & $-1.000=5.8$ & $1.000=6.2$ & 6 & 0.137199 \\
\hline
\end{tabular}

*mean \pm SD (Standard deviation), n=3

Table 2: Representation of experimental design for robustness testing with factors and obtained responses

\begin{tabular}{|c|c|c|c|c|c|c|}
\hline Std & Run & Factor 1 & Factor 2 & Factor 3 & Response 1 & Response 2 \\
\hline 04 & 1 & 1.2 & 65 & 6 & 1.01 & 2.15 \\
\hline 09 & 2 & 1 & 55 & 5.8 & 3.01 & 2.48 \\
\hline 03 & 3 & 0.8 & 65 & 6 & 2.98 & 2.01 \\
\hline 12 & 4 & 1 & 65 & 6.2 & 2.25 & 1.85 \\
\hline 05 & 5 & 0.8 & 60 & 5.8 & 3.05 & 2.07 \\
\hline 15 & 6 & 1 & 60 & 6 & 3.24 & 1.34 \\
\hline 06 & 7 & 1.2 & 60 & 5.8 & 1.21 & 2.21 \\
\hline 14 & 8 & 1 & 60 & 6 & 3.21 & 1.32 \\
\hline 16 & 9 & 1 & 60 & 6 & 3.22 & 1.33 \\
\hline 11 & 10 & 1 & 55 & 6.2 & 3 & 2.21 \\
\hline 17 & 11 & 1 & 60 & 6 & 1.85 & 1.31 \\
\hline 02 & 12 & 1.2 & 55 & 6 & 1.95 & 1.95 \\
\hline 08 & 13 & 1.2 & 60 & 6.2 & 3.09 & 2.01 \\
\hline 07 & 14 & 0.8 & 60 & 6.2 & 1.2 & 2.05 \\
\hline 18 & 15 & 1 & 60 & 6 & 3.1 & 1.33 \\
\hline 01 & 16 & 0.8 & 55 & 6 & 2.21 & 2.61 \\
\hline 10 & 17 & 1 & 65 & 5.8 & 1.2 & 1.89 \\
\hline 13 & 18 & 1 & 60 & 6 & 1.21 & 1.31 \\
\hline
\end{tabular}

Factor 1: flow rate (A), Factor 2: mobile phase-organic phase (B), Factor 3: $\mathrm{pH}(\mathrm{C})$, Response 1: resolution between RC A and RCB ( $\left.\mathrm{Y}_{1}\right)$ and Response 2: tailing of $\mathrm{OLZ}\left(\mathrm{Y}_{2}\right)$.

Table 3: ANOVA results for olanzapine

\begin{tabular}{|c|c|c|c|c|c|c|}
\hline \multicolumn{7}{|c|}{ Data representing the values of response Y1 (Resolution between RC A and RC B) } \\
\hline Source & Squares & df & Mean square & F-Value & p-value & Prob $>$ F \\
\hline Model & 0.67 & 3 & 0.22 & 4.12 & 0.0273 & Significant \\
\hline A-Flow rate & 0.57 & 1 & 0.57 & 10.40 & 0.0061 & \\
\hline B-Mobile Phase (Organic) & 0.095 & 1 & 0.095 & 1.74 & 0.2088 & \\
\hline $\mathrm{C}-\mathrm{pH}$ & 0.013 & 1 & 0.013 & 0.23 & 0.6372 & \\
\hline \multicolumn{7}{|c|}{ Data representing the values of response Y2 (Tailing of olanzapine) } \\
\hline Source & Squares & df & Mean square & F-value & p-value & Prob $>$ F \\
\hline Model & 0.45 & 9 & 0.050 & 24.23 & $<0.0001$ & Significant \\
\hline A-Flow rate & 0.012 & 1 & 0.012 & 5.65 & 0.0447 & \\
\hline B-Mobile Phase (Organic) & 0.055 & 1 & 0.055 & 26.48 & 0.0009 & \\
\hline C-pH & 0.086 & 1 & 0.086 & 41.24 & 0.0002 & \\
\hline
\end{tabular}

*mean \pm SD (Standard deviation), $\mathrm{n}=3$

\section{Quality parameters}

In order to perceive the feasibility of the optimized method, the performance of the of the methods in terms of specificity, linearity, accuracy, precision, the limit of detection (LOD) and limit of quantitation (LOQ) were studied.

Specificity of the system was performed by the analysis of blank, standard solution, individual impurity solution and sample solution 
spiked with known impurities at specification. The outcomes reveled that no matrix interference was observed from the blank at the same retention time of OLZ and impurity peaks. The obtained chromatogram of spiked sample revealed that the impurities were well separated and also the peak purity data reveals that there were no co-eluting peaks and no interference of impurities at the retention time of analyte peak. The specificity data, peak purity and retention time (RT) are compiled in table 4.

Linearity of the method was determined by analyzing standard solution at different concentration levels. The range for linearity was found to be $10-100 \mu \mathrm{g} / \mathrm{ml}$. The coefficient of correlation $\left(\mathrm{R}^{2}>0.9999\right)$. Linearity of the OLZ assay and organic impurities has been presented in table 4 .

Accuracy of the system was studied by estimating percent recoveries of the studied compounds, found between $99 \%$ to $100 \%$. Recovery of OLZ,RC A,RC B and RC C were shown in table 4. The obtained data for OLZ sample were within range.

Precision of the developed method was by performed by analyzing a standard solution of known concentration, the six individual injections were performed. The values in terms of RSD\% were found lower than $2 \%$. As the obtained values were found very low, it represents that the method is precise.

LOD and LOQ of the system were estimated based on the standard deviation of response and slope.

The LOQ for OLZ, RC A, RC B and RC C were 0.39, 0.02, 0.007 and $0.02 \mu \mathrm{g} / \mathrm{ml}$ respectively. The LOD for OLZ, RC A, RC B and RC C were $0.16,0.0055,0.0023$ and $0.0060 \mu \mathrm{g} / \mathrm{ml}$, respectively. The excellent quality parameters were achieved and could be applied for the study of such types of compounds.

Table 4: Data representing system suitability, accuracy and linearity of olanzapine

\begin{tabular}{|c|c|c|c|c|}
\hline Statistical parameter & Olanzapine & Olanzapine RC A & Olanzapine RC B & Olanzapine RC C \\
\hline Retention time tr (min) & 11.65 & 4.20 & 5.50 & 7.60 \\
\hline Resolution & 10.25 & - & 3.21 & 4.95 \\
\hline Accuracy at $40 \%$ & 99.74 & 98.81 at $0.05 \%$ & 98.95 at $0.05 \%$ & 98.12 at $0.05 \%$ \\
\hline Accuracy at $100 \%$ & 99.65 & 99.85 at $0.40 \%$ & 99.12 at $0.40 \%$ & 99.64 at $0.40 \%$ \\
\hline Accuracy at $160 \%$ & 99.12 & $99.51 \%$ at $1.0 \%$ & $99.21 \%$ at $1.0 \%$ & $99.67 \%$ at $1.0 \%$ \\
\hline Concentration range $(\mu \mathrm{g} / \mathrm{ml})$ & $10-100$ & $0.05-1.0$ & $0.05-1.0$ & $0.05-1.0$ \\
\hline Regression equation & $33004 x+32.15$ & $24188 x+31.71$ & $24332 x+22.66$ & $26746 x+204.3$ \\
\hline Correlation coefficient $\left(\mathrm{r}^{2}\right)$ & 0.9999 & 0.9999 & 0.9999 & 0.9999 \\
\hline Slope & 33004 & 24188 & 24332 & 26746 \\
\hline Intercept & 32.15 & 31.71 & 22.66 & 204.3 \\
\hline Limit of Detection (LOD) $(\mu \mathrm{g} / \mathrm{ml})$ & 0.16 & 0.0055 & 0.0023 & 0.0060 \\
\hline Limit of Quantitation (LOQ) $(\mu \mathrm{g} / \mathrm{ml})$ & 0.39 & 0.02 & 0.007 & 0.02 \\
\hline
\end{tabular}

\section{Forced degradation}

In order to study the forced dedradation of the studied compound various paraters for instance stress study, acid base stress testing, thermal stress testing, oxidative stress testing, photostability, stability in analytical solution and robustness incorporating experimental design were investigated [19]. Stress study were perfomred to detect the degradation of drug product under the influence of light, temperature, $\mathrm{pH}$, or water, or by reaction with an excipient and/or the immediate container/closure system. It was calculated by comparing the assay of degraded sample with control sample using mass balance [20] and studied as per ICH guidelines.

Acid Base stress testing was carried out to forcelly the degrade a drug substance into its primary degradation products by exposure to acidic and basic conditions over time. Acid testing was done by taking samples and was treated separately with $5.0 \mathrm{ml}$ of $0.1 \mathrm{~N}$ Hydrochloric acid and kept on bench top for $60 \mathrm{~min}$. Then the treated sample was analyzed and tabulated. For base degradation study, API was treated separately with $5 \mathrm{ml}$ of $1.0 \mathrm{~N}$ Sodium hydroxide and kept on bench top for $60 \mathrm{~min}$. The treated samples were analyzed acccording to the specified method and results were represented in table 5 .

The thermal stress testing was performed by taking sample solution at $105{ }^{\circ} \mathrm{C}$ for $12 \mathrm{~h}$. Then the sample was analysed for degradation products by the optimized HPLC-UV method. The achieved outcomes have been demonstrated in table 5 .

Oxidative studies were performed using a solution of $\mathrm{H}_{2} \mathrm{O}_{2}$. In this method, drug sample was treated separately with $5 \mathrm{ml}$ of $0.3 \% \mathrm{v} / \mathrm{v}$ solution $\mathrm{H}_{2} \mathrm{O}_{2}$ and left for $60 \mathrm{~min}$ at room temperature. Finally, $\mathrm{H}_{2} \mathrm{O}_{2}$ treated sample was analysed by the specified method and data shown in table 5 .

Photostability, pharmaceutical drugs and drug substsnces are mostly exposed to highly energetic electromagnetic radiations like ultra-violet and visible light. The sample and control were exposed to both the cool white fluorescent and near ultraviolet lamp. According to ICH guidelines, there is specific exposure of $5 \mathrm{X}$ and 10 $\mathrm{X} 200$ watth $/ \mathrm{m}^{2}$ for solid drug substances. ICH guidelines specify exposure of 1.2 X 106 lux hours for fluorescence.

Table 5: Forced degradation of olanzapine

\begin{tabular}{|c|c|c|c|c|c|c|}
\hline Mode of degradation & Condition & Period & Purity angle & Purity threshold & \% Assay & \% Drug degradation \\
\hline Control Sample(As such) & No treatment & - & 0.085 & 0.232 & 100.35 & - \\
\hline Acid degradation & $0.1 \mathrm{~N} \mathrm{HCl}$ & $60 \mathrm{~min}$ & 0.066 & 0.237 & 96.52 & 3.82 \\
\hline Base degradation & $1 \mathrm{~N} \mathrm{NaOH}$ & $60 \mathrm{~min}$ & 0.096 & 0.239 & 98.43 & 1.91 \\
\hline Peroxide degradation & $0.3 \% \mathrm{H}_{2} \mathrm{O}_{2}$ & $60 \mathrm{~min}$ & 0.058 & 0.233 & 98.85 & 1.49 \\
\hline Thermal degradation & $105^{\circ}$ & $12 \mathrm{~h}$ & 0.067 & 0.233 & 100.45 & 0.43 \\
\hline Photolytic degradation & $254 \mathrm{~nm}$ & $10 \mathrm{~d}$ & 0.085 & 0.241 & 99.92 & 0.10 \\
\hline
\end{tabular}

During all above drug degradation studies, it was observed that no major unknown degradation was found, and in all above degradation condition was $0.10 \%$ to $3.82 \%$ in OLZ. Only know impurities were found to be increased and degradation was calculated based on assay obtained after final analysis. From the data obtained from forced degradation studies shows that method is specific for determination of OLZ pure drug and results were shown in fig. 3 and table 4

Stability of analytical solutions were determined by preparing standard solution, sample solution according to test method and 
then injected in HPLC, at initial amd different time intervals for $24 \mathrm{~h}$ and then determined cumulative \% RSD for peak areas of OLZ. No changes in assay values was observed for $24 \mathrm{~h}$ indicating stability of drug in the solvent used during analysis.

The robustness incorporating experimental design was evaluated by Box-Behnken design (BBD), in which 3 dependent variables like flow rate (A), mobile phase-organic phase (B) and $\mathrm{pH}(\mathrm{C})$ simultaneously, selected response variables as while resolution between RC A and $\mathrm{RC} B\left(\mathrm{Y}_{1}\right)$ and ftailing of $\mathrm{OLZ}\left(\mathrm{Y}_{2}\right)$ were taken as robustness parameters. For the present applied BBD, following 18 runs by considering multiple parameters together instead of selecting individual parameter when performed manually. So most appropriate possibilities were selected, executed and reported in table 1 and the obtained response derived after implementation of experimental design were tabulated in table 2 Implementation of BBD yields various models, based on the suggested models execution of several systems, responses like resolution between RC A and RC B, tailing of OLZ were observed. The effects of uncontrolled factors were minimized to prevent unwanted influence on response, so randomized method was opted for each experiment. The observations obtained from BBD suggested the model as second degree with quadratic domain values for response $\mathrm{Y}_{1}(\mathrm{r} 2=0.4691)$ and $Y_{2}(r 2=0.9646)$ respectively. The observed data was recorded, analyzed and validated by implementing ANOVA to all response variables for examination of significance of model, the ANOVA data showed significant differences in the values of responses as observed in table III. The predicted values for the dependent factors like, flow rate $(\mathrm{A})$, mobile phase-organic phase $(\mathrm{B})$ and $\mathrm{pH}(\mathrm{C})$, were within the accepted range with estimated model F-value 4.12 for response Y1, exhibiting highly significant with model p-value 0.0273 , indicating only $2.73 \%$ chance of higher model F-value, due to noise. From the obtained ANOVA data for predicted response Y2 model F-value 24.23, exhibiting highly significant with pvalue $<0.0001$, representing $0.01 \%$ chance of higher model F-value because of noise. Finally, the above models suggested that as estimated values for all the responses were nearer to real obtained values, hence exhibiting better accuracy and precision for the observed data as observed from fig. 4.
Control sample

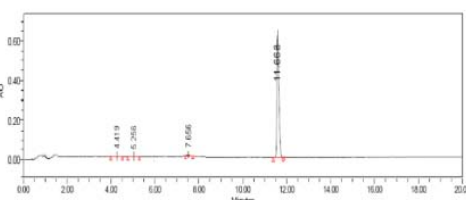

Base degradation

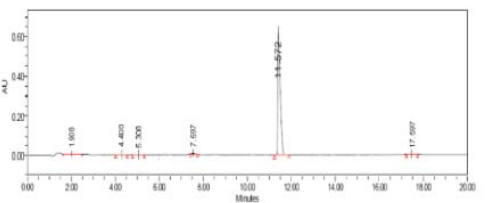

Thermal degradation

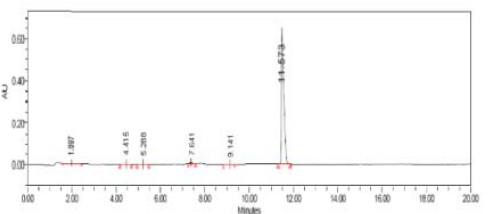

Acid degradation

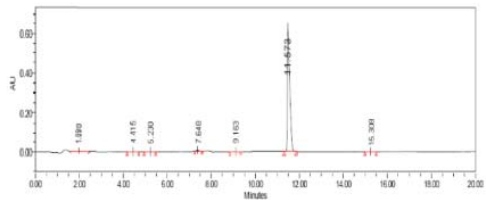

Peroxide degradation

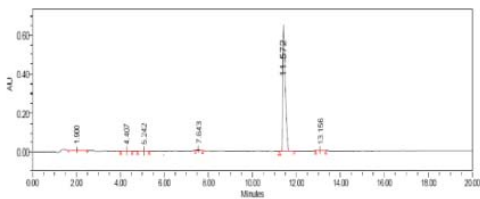

Photolytic degradation

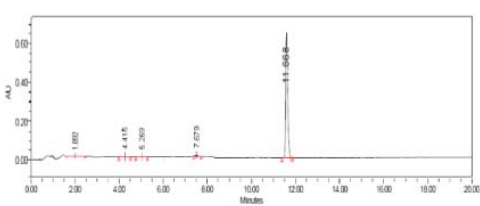

Fig. 3: Chromatogram of force degradations 

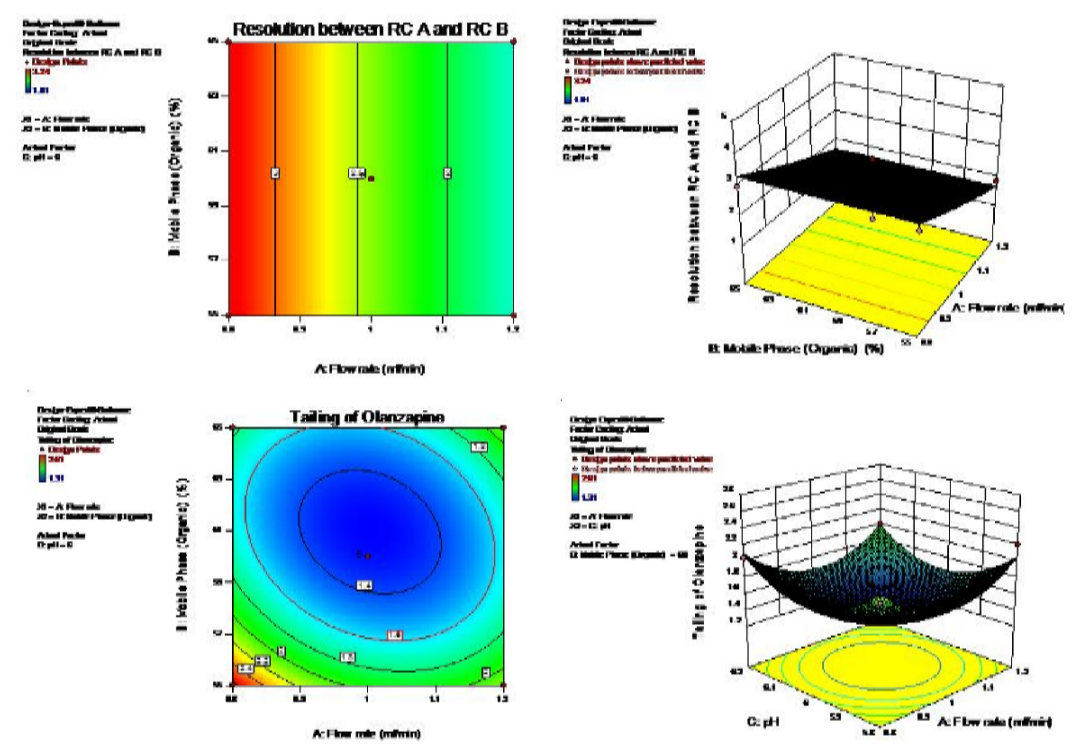

Fig. 4: Contour plots and three dimensional response surfaces effect of factor A, B, and C on responses Y1 and Y2

\section{CONCLUSION}

In the present study, we have developed a systemic, simple isocratic reversed-phase HPLC-UV method for estimation of OLZ and its OI A (RC A), B (RC B) and C (RC C) and simultaneously validated according to ICH guidelines. It was observed that, the current method was suitable for determinations of active pharmaceutical ingredients of OLZ. In method validation, inter and intra day variations were well within limit and was found to be precised with \%RSD less than 2 . The proposed method was found to be specicfic, selective, accurate, precise, and reproducible. Application of Box-Behnken design for the optimization of method showed that little changes in mobile phase and flow rate affect the response while $\mathrm{pH}$ has no affect. That's why strict monitoring of the above mentioned two factors during chromatographic testing was required. The results obtained from the validation were found satisfactory and offers a rapid and simple sample preparation which can facilitate the routine analysis of OLZ. From the statistical study data it can be concluded that method can be successfully applied to different marketed brands.

\section{ACKNOWLEDGEMENT}

All authors are thankful to Alkem laboratories (P) Ltd, Mumbai for providing the gift sample of drug. We also want to express our thankfulness and gratitude to Y B Chavan College of pharmacy, Maharashtra, India, for smooth execution of present $\mathrm{PhD}$ research work.

\section{FUNDING}

Nil

\section{AUTHORS CONTRIBUTIONS}

All authors have contributed equally.

\section{CONFLICT OF INTERESTS}

All the authors declare that there is no conflict of interest by all of us.

\section{REFERENCES}

1. Revanasiddappa H, Deepakumari H. Highly sensitive spectrophotometric method for the quantitative determination of olanzapine in its pure and in pharmaceutical dosage forms. J Sci Indus Res 2014;73:41-105.

2. Raggi M, Casamenti C, Mandrioli R, Fanali S, De Ronchi D, Volterra V. Determination of the novel antipsychotic drug olanzapine in human plasma using HPLC with amperometric detection. Chromatographia 2000;51:562-6.

3. Leucht S, Corves C, Arbter D, Engel RR, Li C, Davis JM. Secondgeneration versus first-generation antipsychotic drugs for schizophrenia: a meta-analysis. Lancet 2009;373:31-41.
4. Bhana N, Perry CM. Olanzapine: a review of its use in the treatment of bipolar I disorder. CNS Drugs 2001;15:871-904.

5. Pradhan K, Mishra U, Pattnaik S, Panda C, Sahu K. Development and validation of a stability-indicating UV spectroscopic method for candesartan in bulk and formulations. Indian J Pharm Sci 2014;6:67-72.

6. Basavaiah K, Abdulrahman SA. Sensitive and selective methods for the determination of olanzapine in pharmaceuticals using $\mathrm{N}$-bromosuccinimide and two dyes. Int $\mathrm{J}$ Chem Tech Res 2010;2:660-8.

7. Krebs A, Starczewska B, Puzanowska Tarasiewicz H, Sledz J. Spectrophotometric de termination of olanzapine by its oxidation with $\mathrm{N}$-bromosuccinimide and cerium (IV) sulfate. Anal Sci 2006;22:829-33.

8. Cui D, Li Y, Lian M, Yang F, Meng Q. Development of a simple and stability-indicating RP-HPLC method for determining olanzapine and related impurities generated in the preparative process. Analyst 2011;136:3149-56.

9. D'Arrigo C, Migliardi G, Santoro V, E Spina E. Determination of olanzapine in human plasma by reversed-phase highperformance liquid chromatography with ultraviolet detection. Ther Drug Monit 2006;28:388-93.

10. Murthy AR, Babu KR, Vekariya N. Analytical method development and validation of olanzapine by highperformance liquid chromatography. Int J Pharm Sci Drug Res 2015;7:188-92.

11. Rao RN, Raju AN, Narsimha R, Babu GR. Isolation and characterization of process-related impurities of olanzapine using HPLC and ESI-MS/MS. J Sep Sci 2008;301:107-18.

12. Niedermeier S, Scriba GK. A quality by design-based approach to a capillary electrokinetic assay for the determination of dextromepromazine and levomepromazine sulfoxide as impurities of levomepromazine. J Pharm Biomed Anal 2017;146:402-9.

13. Peraman R, Bhadraya Padmanabha YR. Analytical quality by design: a tool for regulatory flexibility and robust analytics. Int J Anal Chem 2015;2015:1-9.

14. Khanam N, Alam MI, Ali Y, Siddiqui AR. A review on optimization of drug delivery system with experimental designs. Int J Appl Pharm 2018;10:7-12.

15. Alam MI, Siddiqui AR, Khanam N, Kamaruddin SJ. A multivariate quantification of box-behnken design assisted method development and validation of dextromethorphan hydrobromide and desloratadine simultaneously by reversephase HPLC in in-house syrup formulation. J Sep Sci 2020;43:110.

16. Tome T, Zigart N, Casar Z, Obreza A. Development and optimization of liquid chromatography analytical methods by 
using AQbD principles: overview and recent advances. Organic Process Res Dev 2019;23:1784-802.

17. Alam I, Khanam N, Shaikh JK, Ganguly S. Quality by design-a recent trend in pharmaceutical industries. World J Pharm Res 2016;5:608-20.

18. Tumpa, Stajic A, Jancic Stojanovic B, Medenica M. Quality by design in the development of hydrophilic interaction liquid chromatography method with gradient elution for the analysis of olanzapine. J Pharm Biomed Anal 2017;134:18-26.
19. Reddy BA, Alam MI, Khanam N, Krishnanand PR. An innovative method development and forced degradation studies for simultaneous estimation of sofosbuvir and ledipasvir by RP HPLC. Int J Pharm Pharm Sci 2019;11:34-41.

20. Naazneen S, Sridevi A. Development of assay method and forced degradation study of valsartan and sacubitril by RPHPLC in tablet formulation. Int J Appl Pharm 2017;9:9-15. 